\title{
Comunicación
}

\section{Reporte de doble pared en túbulos hepatopancreáticos en camarones marinos, error conceptual e imposibilidad tisular}

\author{
Report of double wall in hepatopancreatic tubules in marine shrimp, conceptual \\ error and tissue impossibility
}

\author{
Alexander Varela
}

\section{Resumen}

En la presente nota se citan algunas patologías bacterianas con capacidad de lesionar el hepatopáncreas de camarones marinos de cultivo, así como detalles de algunas de las técnicas de monitoreo utilizadas para su estudio, enfatizando en el análisis en fresco. Esta técnica es ampliamente utilizada en las granjas camaroneras por su bajo costo, mínimo tiempo de respuesta, corto tiempo de entrenamiento y practicidad. Se aborda el tema de la llamada «doble pared» reportada con cierta frecuencia por algunos analistas, presentando argumentos para entender el posible origen de este artefacto, y se sustenta con información la imposibilidad de formación de paredes múltiples en los túbulos. Para esto, se describe la estructura normal del epitelio tubular de estos animales, tanto en estadios de normalidad, así como bajo condiciones patológicas.

Palabras clave: hepatopáncreas, túbulos, doble pared

\section{Abstract}

In this note, some bacterial pathologies with the capacity to injure the hepatopancreas of farmed marine shrimp are cited, as well as details of some of the monitoring techniques used for their study, emphasizing the fresh analysis. This technique is widely used in

\footnotetext{
${ }^{1}$ Consultor en sanidad acuícola, Sonora, México

${ }^{2}$ E-mail: alexander.varela@gmail.com
}

Recibido: 1 de marzo de 2021

Aceptado para publicación: 27 de agosto de 2021

Publicado: 27 de octubre de 2021

CLos autores. Este artículo es publicado por la Rev Inv Vet Perú de la Facultad de Medicina Veterinaria, Universidad Nacional Mayor de San Marcos. Este es un artículo de acceso abierto, distribuido bajo los términos de la licencia Creative Commons Atribución 4.0 Internacional (CC BY 4.0) [https:// creativecommons.org/licenses/by/4.0/deed.es] que permite el uso, distribución y reproducción en cualquier medio, siempre que la obra original sea debidamente citada de su fuente original 
shrimp farms due to its low cost, minimum response time, short training time and practicality. The issue of the so-called «double wall» reported with some frequency by some analysts is addressed, presenting arguments to understand the possible origin of this artifact, and the impossibility of the formation of multiple walls in the tubules is supported with information. For this, the normal structure of the tubular epithelium of these animals is described, both in normal stages, as well as under pathological conditions.

Key words: hepatopancreas, tubules, double wall

\section{Introducción}

Históricamente, la incidencia de infecciones bacterianas en camarones Penaeidos ha sido mayormente atribuida a brotes causados por especies del género Vibrio, ocasionando Necrosis Séptica del Hepatopáncreas - NSHP (Prieto y Rodríguez, 1993; Lightner, 1996) y por la bacteria intracelular Hepatobacter penaei en los brotes de la hepatopancreatitis necrotizante (Lightner, 1996; Vincent y Lotz, 2007, OIE, 2019). En los últimos años se han presentado patologías bacterianas emergentes o reemergentes que también pueden afectar este órgano, tal como ha sido el caso de la Espiroplasmosis (Nunan et al., 2004; Heres et al., 2011; Pantoja y Lightner, 2014a), la Estreptococosis (Hasson et al., 2009) y la Necrosis Aguda del Hepatopáncreas (Tran et al., 2013; Nunan et al., 2014; Pantoja y Lightner, 2014b, OIE, 2019).

Esta diversidad de agentes bacterianos ha demandado la necesidad de monitorear con mayor rigurosidad el estado sanitario de los animales de cultivo desde granja. Esto ha motivado que los procedimientos de análisis básicos hayan evolucionado en forma gradual hacia otros ensayos diagnósticos más sensibles, como bacteriología, histopatología y técnicas moleculares, siendo común la combinación de técnicas (Lightner, 1996; Varela y Choc, 2020). Pese a ello, el análisis en fresco continúa siendo una de las técnicas más utilizadas en los programas de monitoreo efectuados en las granjas, lo cual es fácil- mente comprensible considerando su bajo costo, la rapidez de ejecución y el relativo corto tiempo de entrenamiento requerido para el personal a cargo (Lightner, 1996; Morales-Covarrubias, 2010; Varela y Choc, 2020).

El análisis en fresco brinda información sobre el estado general de los camarones, incluyendo datos sobre la condición del hepatopáncreas y permite procesar un gran número de animales en poco tiempo. Su principal limitante lo constituyes su baja sensibilidad y especificidad, si se le compara con técnicas como la histopatología (Lightner, 1996; OIE, 2019; Varela, 2018; Varela y Choc, 2020). Aun así, es posible obtener resultados preliminares (Morales-Covarrubias, 2010), con los cuales se pueden iniciar acciones correctivas en granja, pero requieren de un cuidadoso análisis y una correcta interpretación de las observaciones realizadas (Varela y Choc, 2020).

En el presente reporte se citan algunas patologías bacterianas con capacidad de lesionar el hepatopáncreas de camarones marinos de cultivo, así como detalles de algunas de las técnicas de monitoreo utilizadas para su estudio, enfatizando en el análisis en fresco.

\section{Reportes de Análisis en Fresco}

Durante los últimos años, paralelo al incremento de la incidencia de bacteriosis en hepatopáncreas, se ha tornado cada vez más común encontrar reportes de análisis en fresco que mencionan la presencia de una «do- 


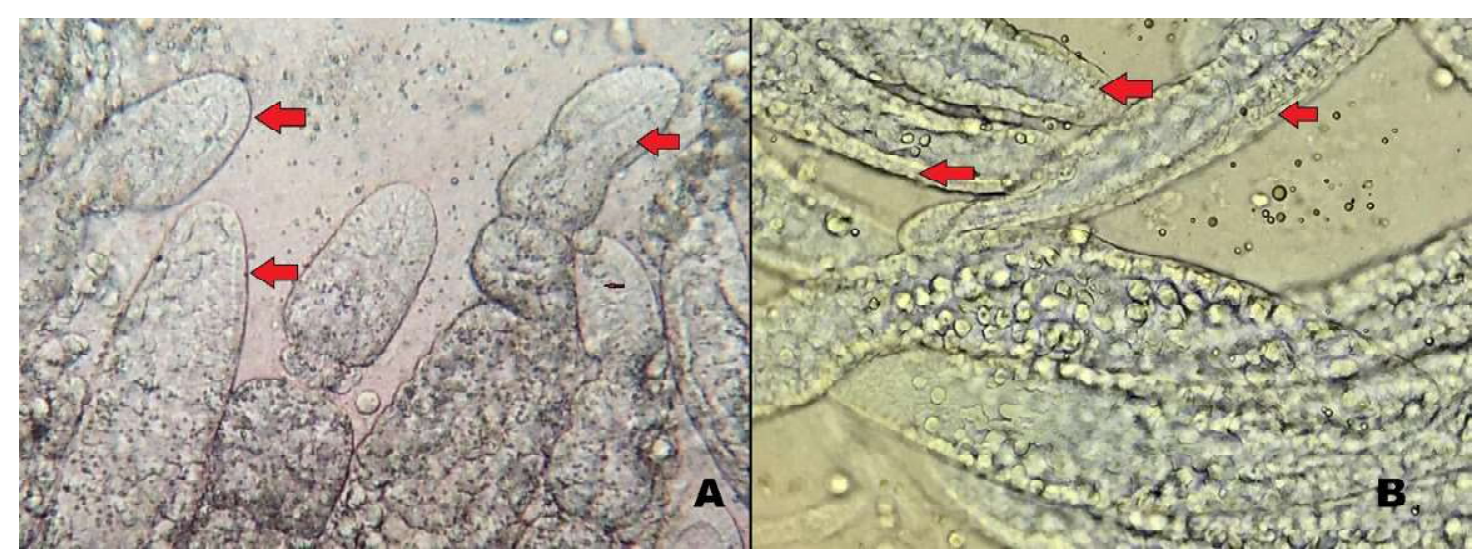

Figura 1. Fotografía de montaje en fresco de dos hepatopáncreas de camarones Penaeidos. Las flechas señalan algunas regiones con las supuestas «dobles paredes». Sin tinción, $400 \mathrm{X}$

ble pared» en los túbulos del hepatopáncreas, siendo estos reportes asociados a condiciones lesionales como las mostradas en la Figura 1.

Con el fin de comprender la estructura normal de los túbulos hepatopancreáticos se debe estar familiarizado con su anatomía, tanto en observaciones en fresco, como en montajes histológicos de animales sanos y mediante la constante revisión de literatura especializada. Los túbulos han sido descritos como estructuras formadas por un epitelio simple, de diferentes tipos de células columnares, dispuestas sobre una membrana basal. Estos túbulos poseen además un lumen central, en el cual se realiza la digestión extracelular e intrace-lular de las partículas de pequeño tamaño asimiladas por los camarones (Bell y Lightner, 1988; Lightner, 1996).

Dichos túbulos hepatopancreáticos presentan una organización definida y sus poblaciones celulares han sido caracterizadas, iniciando con las llamadas células E o embrionarias, indiferenciadas, las cuales se encuentran en los extremos distales de los túbulos. Estas presentan alta actividad mitótica y dan lugar a la diferenciación en los demás tipos de células, designadas como F, B y R (Figura 2), las cuales se diferencian mientras migran por el túbulo hacia la región proximal, lugar en el cual pueden ser degradadas o liberadas mediante secreción holocrina (Bell y Lightner, 1988; Caceci et al., 1998).

Esta disposición tisular, en ausencia de patologías o deficiencias nutricionales, está conformada por células sanas y normales, las cuales presentan una gran cantidad de vacuolas y organelas que impiden o dificultan «ver a través del túbulo». De modo que, mediante análisis en fresco, solo se aprecia por lo general la cara externa de las células epiteliales, quedando eclipsada la presencia del lumen tubular.

En el caso de muestras de hepatopáncreas con lesiones de tipo patológico e, incluso, con deficiencias nutricionales severas, la cantidad de reservas y por tanto de vacuolas presentes es mínima o nula, facilitando que la luz del microscopio atraviese los tejidos y se pueda observar tanto el extremo externo como la cara interna de las células epiteliales sobre la membrana basal (Figura 1). Esto podría dar lugar a un error de interpretación, siendo reportado como una «doble 


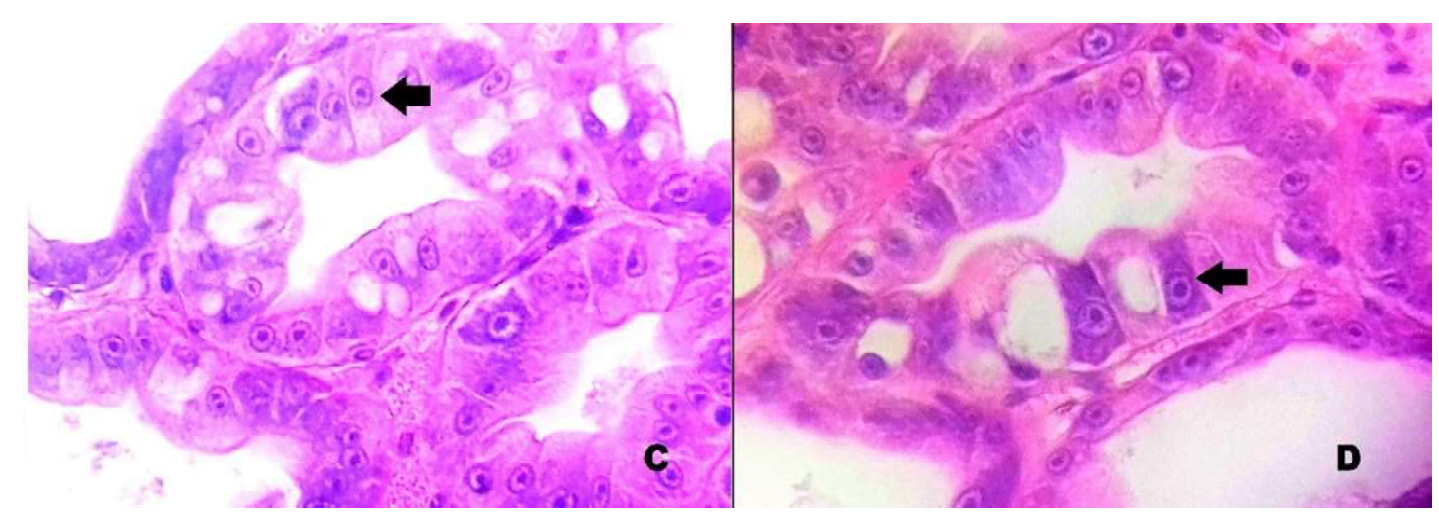

Figura 2. Cortes histológicos de hepatopáncreas sanos de camarones Penaeidos. Se observan cortes transversales de los túbulos con diferentes tipos celulares sin presentar capas superpuestas (epitelio monocapa). Tinción H\&E. 400X

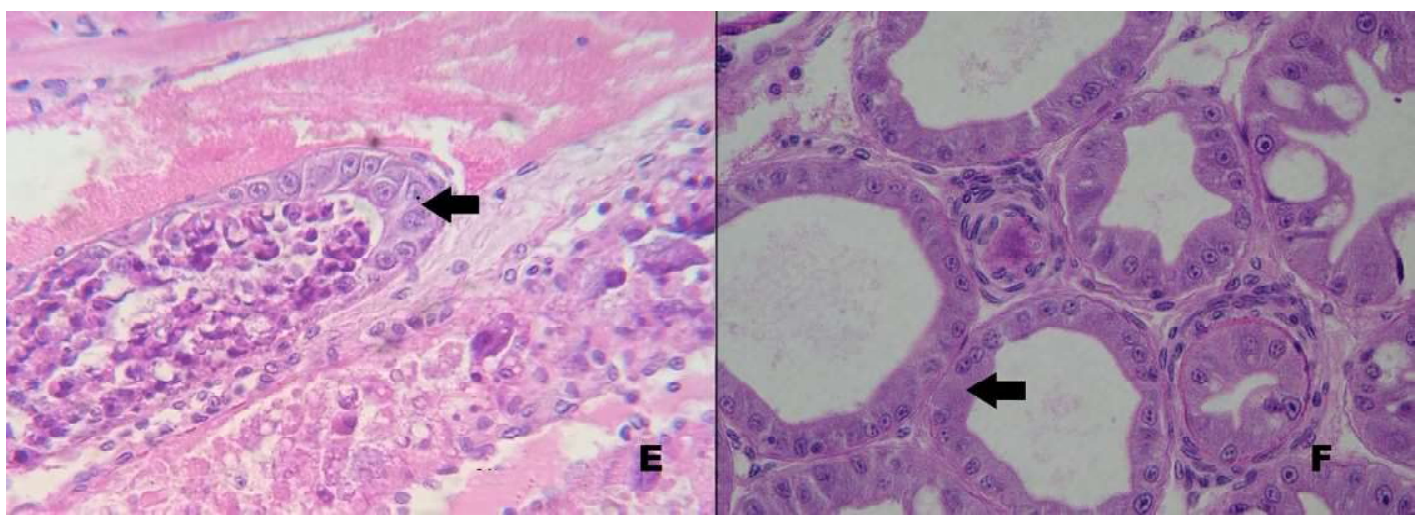

Figura 3. Cortes histopatológicos de hepatopáncreas de camarones Penaeidos afectados por Necrosis Aguda del Hepatopáncreas - AHPND (E) y por atrofia severa en un cuadro combinado de NHP y Necrosis Séptica del Hepatopáncreas - SHPN (F). A pesar de los procesos patológicos solo se observan las estructuras tubulares monocapas. Tinción H\&E. 400X

pared», cuando en realidad se presenta una sola capa de células, pero en circunstancias que permiten ver sus dos lados. En estos casos sería correcto reportar «túbulos vacios» y no «dobles paredes».

En la Figura 3 se presentan tejidos procesados mediante histopatología de rutina. En este caso, de muestras con lesiones patológicas importantes. En la imagen E, podemos ver un corte longitudinal de túbulos afectados por la Necrosis aguda del hepatopáncreas, o AHPND, con un severo desprendimiento celular. En la imagen F, se presenta un corte transversal sobre túbulos con infección por Necrosis séptica del hepatopáncreas y Hepatopancreatitis necrotizante, con túbulos fuertemente atrofiados. En ambos casos, pese a la severidad de las lesiones y a la desorganización asociada a las infecciones, no se 
presentan dobles paredes, siendo consistente con los argumentos expuestos en las líneas anteriores.

\section{Consideraciones Finales}

Los hepatopáncreas de los camarones penaeidos han sido claramente descritos y caracterizados por múltiples publicaciones. En todas ellas existe concordancia al describir a los túbulos como estructuras conformadas por epitelios simples, anclados a membranas basales y formados por diferentes tipos de células (Bell y Lightner, 1988; Caceci et al., 1988).

Las patologías bacterianas asociadas a los hepatopáncreas, generan diferentes tipos de lesiones y alteraciones anatomopatológicas con severidad variable, pero hasta el presente no se han reportado epitelios superpuestos o multiestratificados, condición necesaria para la existencia de una doble pared. Los reportes de «doble pared», generados de análisis en fresco sobre túbulos hepatopancreáticos de camarones marinos deben ser considerados como «túbulos vacíos», «atrofiados» o «degradados», dado que la doble pared es un efecto originado en la traslucidez del tejido observado. No es posible que se presenten lesiones como las descritas de doble pared observables en fresco, pero ausentes en análisis histológico, caracterizado este último por presentar una mayor fidelidad entre los tejidos fijados y las condiciones in vivo. Los reportes de doble pared, sin ser anatomopatológicamente precisos, corresponden a condiciones anormales del órgano, no patognomónicas y se deben realizar acciones con el fin de identificar la causa y las medidas de control pertinentes.

\section{Literatura Citada}

1. Bell TA; Lightner DV. 1988. A handbook of normal Penaeid shrimp histology. Baton Rouge, USA: World Aquaculture Society. $114 \mathrm{p}$.
2. Caceci T, Neck KF, Lewis DF, Si, RF. 1988. Ultrastructure of the hepatopancreas of the pacific white shrimp Penaeus vannamei (Crustacea: Decapoda). J Mar Biol Ass UK 68: 323-337. doi: $10.1017 / \mathrm{S} 002531540005222 \mathrm{X}$

3. Hasson KW; Wyld EM, Fan Y, Lingsweiller SW, Weaver SJ, Cheng J, Varner PW. 2009. Streptococcosisin farmed Litopenaeus vannamei: a new emerging bacterial disease of penaeid shrimp. Dis Aquat Org 86: 93-106. doi: 10.3354/dao02132

4. Heres A, Redman R, Lightner DV. 2011. Histopathology of Spiroplasma penaei systemic infection in experimentally infected pacific white shrimp, Penaeus vannamei. Isr J Aquac 63: 11.589

5. Lightner DV. 1996. A handbook of shrimp pathology and diagnostic procedures for diseases of cultured penaeid shrimp. Baton Rouge, USA. World Aquaculture Society. $256 \mathrm{p}$.

6. Morales-Covarrubias MS. 2010. Enfermedades del camarón: detección mediante análisis en fresco e histopatología. México DF: Ed Trillas. 122 p.

7. Nunan L, Lightner DV, Pantoja CR, Gomez-Jimenez S. 2014. Detection of acute hepatopancreatic necrosis disease (AHPND) in Mexico. Dis Aquat Org 111: 81-86. doi: 10.3354/dao02776

8. Nunan LM, Pantoja CR, Salazar M, Aranguren F, Lightner DV. 2004. Characterization and molecular methods for detection of a novel spiroplasma pathogenic to Penaeus vannamei. Dis Aquat Org 62: 255-264. doi: 10.3354/ dao062255

9. [OIE]. Organización Mundial de Sanidad Animal. 2019. Manual de diagnóstico en animales acuáticos. Paris, Francia. [Internet]. Disponible en: https:/ /www.oie.int/es/normas/manualacuatico/

10. Pantoja CR, Lightner DV. $2014 a$. EMS/AHPND descripción de la enfermedad en Asia y América. En: Morales 
V, Cuéllar-Anjel J (eds). Patología e inmunología de camarones penaeidos. Guía Técnica. Panamá: OIRSA. p p172-177.

11. Pantoja CR, Lightner DV. 2014 b. Spiroplasma penaei. En: Morales V, Cuéllar-Anjel J (eds). Patología e inmunología de camarones penaeidos. Guía Técnica. Panamá: OIRSA. p 189-191.

12. Prieto A, Rodríguez MC. 1993. Diagnóstico y control de enfermedades bacterianas en camarón de cultivo. Programa cooperativo gubernamental. Proyecto Aquila II: Apoyo a las actividades regionales de acuicultura. Documento de campo No. 14.

13. Tran L, Nunan L, Redman RM, Mohney LL, Pantoja CR, Fitzsimmons K, Lightner DV. 2013. Determination of the infectious nature of the agent of acute hepatopancreatic necrosis syndrome affecting penaeid shrimp. Dis AquatOrg 105: 45-55. doi: 10.3354/ dao02621

14. Varela A. 2018. Patologías del hepatopáncreas en camarones marinos cultivados en América y su diagnóstico diferencial mediante histopatología. AquaTIC 50: 13-30.

15. Varela A, Choc L. 2020. Técnicas diagnósticas para enfermedades bacterianas en camarones. Usos, alcances y limitaciones. Rev Inv Vet Perú 31: e18165. doi: 10.15381/rivep.v31i3.18165

16. Vincent A, Lotz J. 2007. Effect of salinity on transmission of necrotizing hepatopancreatitis bacterium (NHPB) to Kona stock Litopenaeus vannamei. Dis Aquat Org 75: 265-268. 